\title{
Treatment Outcome after Fractionated Conformal Radiotherapy for Hepatocellular Carcinoma in Patients with Child-Pugh Classification B in Korea (KROG 16-05)
}

\author{
Sun Hyun Bae, MD, PhD \\ Hee Chul Park, MD, PhD² \\ Won Sup Yoon, MD, PhD 3 \\ Sang Min Yoon, MD, PhD ${ }^{4}$ \\ In-Hye Jung, $M D, P h D^{4}$ \\ Ik Jae Lee, MD, $P h D^{5}$ \\ Jun Won Kim, MD, PhD 5 \\ Jinsil Seong, MD, PhD ${ }^{6}$ \\ Tae Hyun Kim, MD, PhD \\ Taek-Keun Nam, MD, PhD ${ }^{8}$ \\ Youngmin Choi, MD, PhD ${ }^{9}$ \\ Sun Young Lee, MD, PhD ${ }^{10}$ \\ Hong Seok Jang, MD, $P D^{11}$ \\ Dong Soo Lee, MD, PhD ${ }^{12}$ \\ Jin Hee Kim, MD, PhD ${ }^{13}$
}

${ }^{*}$ A list of author's affiliations appears at the end of the paper.

\author{
Correspondence: Won Sup Yoon, MD, PhD \\ Department of Radiation Oncology, \\ Korea University Ansan Hospital, \\ 123 Jeokgeum-ro, Danwon-gu, Ansan 15355, Korea \\ Tel: 82-31-412-6850 \\ Fax: 82-31-412-4214 \\ E-mail: irionyws@korea.ac.kr
}

Co-correspondence: Sang Min Yoon, MD, PhD Department of Radiation Oncology,

Asan Medical Center, University of Ulsan College of Medicine, 88 Olympic-ro 43-gil,

Songpa-gu, Seoul 05505, Korea

Tel: 82-2-3010-5615

Fax: 82-2-3010-6950

E-mail:drsmyoon@amc.seoul.kr

Received December 11, 2018

Accepted April 9, 2019

Published Online April 10, 2019

*Sun Hyun Bae and Hee Chul Park contributed equally to this work.

\section{Purpose}

There is limited data on radiotherapy (RT) for hepatocellular carcinoma (HCC) in patients with Child-Pugh classification $\mathrm{B}(\mathrm{CP}-\mathrm{B})$. This study aimed to evaluate the treatment outcomes of fractionated conformal RT in HCC patients with CP-B.

\section{Materials and Methods}

We retrospectively reviewed the data of HCC patients with CP-B treated with RT between 2009 and 2014 at 13 institutions in Korea. HCC was diagnosed by the Korea guideline of 2009, and modern RT techniques were applied. Fraction size was $\leq 5$ Gy and the biologically effective dose $(B E D) \geq 40 \mathrm{~Gy}_{10}(\alpha / \beta=10 \mathrm{~Gy})$. A total of 184 patients were included in this study.

\section{Results}

Initial CP score was seven in $62.0 \%$ of patients, eight in $31.0 \%$, and nine in $7.0 \%$. Portal vein tumor thrombosis was present in $66.3 \%$ of patients. The BED ranged from 40.4 to 89.6 $\mathrm{Gy}_{10}$ (median, $56.0 \mathrm{~Gy}_{10}$ ). After RT completion, $48.4 \%$ of patients underwent additional treatment. The median overall survival (OS) was 9.4 months. The local progression-free survival and OS rates at 1 year were $58.9 \%$ and $39.8 \%$, respectively. In the multivariate analysis, non-classic radiation-induced liver disease (RILD) $(p<0.001)$ and additional treatment ( $p$ $<0.001$ ) were the most significant prognostic factors of OS. Among 132 evaluable patients without progressive disease, $19.7 \%$ experienced non-classic RILD. Normal liver volume was the most predictive dosimetric parameter of non-classic RILD.

\section{Conclusion}

Fractionated conformal RT showed favorable OS with a moderate risk non-classic RILD. The individual radiotherapy for CP-B could be cautiously applied weighing the survival benefits and the RILD risks. 


\section{Introduction}

Hepatocellular carcinoma (HCC) is one of the most common malignancies and the second leading cause of cancerrelated death in the world [1]. Because HCC usually develops in patients with underlying liver cirrhosis, the coexistence of two life-threatening conditions of cancer itself and cirrhosis complicates the prognosis [2]. Child-Pugh classification (CP) is the most widely used system to assess the severity of underlying liver cirrhosis. In HCC patients with well-compensated liver function (CP class A, CP-A), the efficacy and safety of various treatment modalities according to the tumor extent are well documented. However, in cases of a borderline liver function (CP-B), liver cirrhosis further limits the applicability of certain treatment modalities because some standard therapies are a strain on the patients or can cause collateral damage to the non-cancerous liver tissue, thereby potentially further aggravating liver dysfunction [3]. A recent review article suggested that the best approach for treating HCC patients with CP-B would be to assess the prognostic weight of the HCC burden in the individual patient compared with that of cirrhosis severity and to adapt eventual tumor treatment to the liver function for tolerability and potential benefit [4].

Although radiotherapy (RT) was previously limited to HCC treatment owing to the low tolerance dose of the whole liver to RT [5], the developments in imaging and the introduction of 3-dimensional conformal radiotherapy (3DCRT) have enabled the delivery of conformal RT to the partial liver. In addition, further development of RT techniques, including intensity-modulated radiotherapy (IMRT), and stereotactic body radiotherapy (SBRT), have been expanded the role of RT for HCC [6]. Hepatic toxicity after RT is defined as radiation-induced liver disease (RILD), which typically occurs between 2 weeks to 3 months after RT, and the overall incidence has been reported to be $0 \%-20 \%[7,8]$. Virtually all prospective and retrospective studies have included patients with CP-A and CP-B only, and the most of those with CP-B were classified as CP-B7 [9]. Culleton et al. [10] retrospectively reported that $63 \%$ of patients had a decline in CP score of $\geq 2$ points after SBRT in HCC patients with CP$B$ or $-C$. In contrast, in subgroup analyses of $\leq 20$ patients with CP-B in few studies, the incidence of RILD was $27 \%$ $63 \%$. This suggest that SBRT should be used with caution or omitted for cases of severely impaired liver function.

Therefore, we performed a retrospective multi-institutional study with a large cohort obtained from 13 institutions of the Korean Radiation Oncology Group (KROG) to evaluate the efficacy and toxicity of fractionated conformal RT for HCC patients with CP-B.

\section{Materials and Methods}

\section{Patient selection}

We retrospectively reviewed the medical records of patients who received RT for HCC at 13 institutions of the KROG. The inclusion criteria were as follows: (1) HCC was diagnosed based on the Korean Liver Cancer Study Group (KLCSG) and the National Cancer Center (NCC) practice guideline of 2009 and was treated with RT between 2009 and 2014 [11]; (2) Eastern Cooperative Oncology Group performance score of $0-2$; (3) CP-B; (4) treatment with modern RT techniques such as 3DCRT or IMRT; and (5) fraction size $\leq 5$ Gy and the biologically effective dose (BED) $\geq 40$ Gy10 when the $\alpha / \beta$ ratio was assumed to be $10 \mathrm{~Gy}$. The exclusion criteria were as follows: (1) huge HCC beyond $60 \%$ of the total liver volume (TLV), for which RT was not feasible according to the KLCSG and NCC practice guideline of 2009; (2) extrahepatic spread beyond the regional lymph nodes; (3) history of previous RT to the liver; (4) history of additional RT for other HCC in the liver within 3 months; and (5) history of malignancies besides HCC within 5 years. A total of 184 patients were included in this study.

\section{Evaluation of hepatic toxicity}

Patients underwent a physical examination, laboratory tests, and computed tomography and/or magnetic resonance imaging to assess hepatic function and evaluate the tumor extent before RT as well as to assess hepatic toxicity and the tumor response at follow-up visits. Hepatic toxicity was categorized as classic and non-classic RILD. Classic RILD included anicteric hepatomegaly, ascites, or elevated alkaline phosphatase more than twice the upper limit of normal value. Non-classic RILD included elevation of liver transaminases more than 5 times the upper limit of normal level or a worsening of CP score of $\geq 2$ points. We defined the occurrence of non-classic RILD in the absence of documented progressive disease within 3 months after the end of RT as significant toxicity. Therefore, we subsequently excluded these patients from the entire study population as shown in Fig. 1 to minimize confounding factors. The remaining 132 patients were evaluated for hepatic toxicity.

For dosimetric analysis, the dose-volumetric values were calculated from dose-volume histograms. The normal liver volume (NLV) was defined as the TLV minus the gross tumor volume in seven institutions and as the TLV minus the planning target volume in six institutions. Doses delivered to specific volumes of the TLV and NLV were evaluated. Due to variations in the fractionation schemes among institutions, all doses were converted into the equivalent 


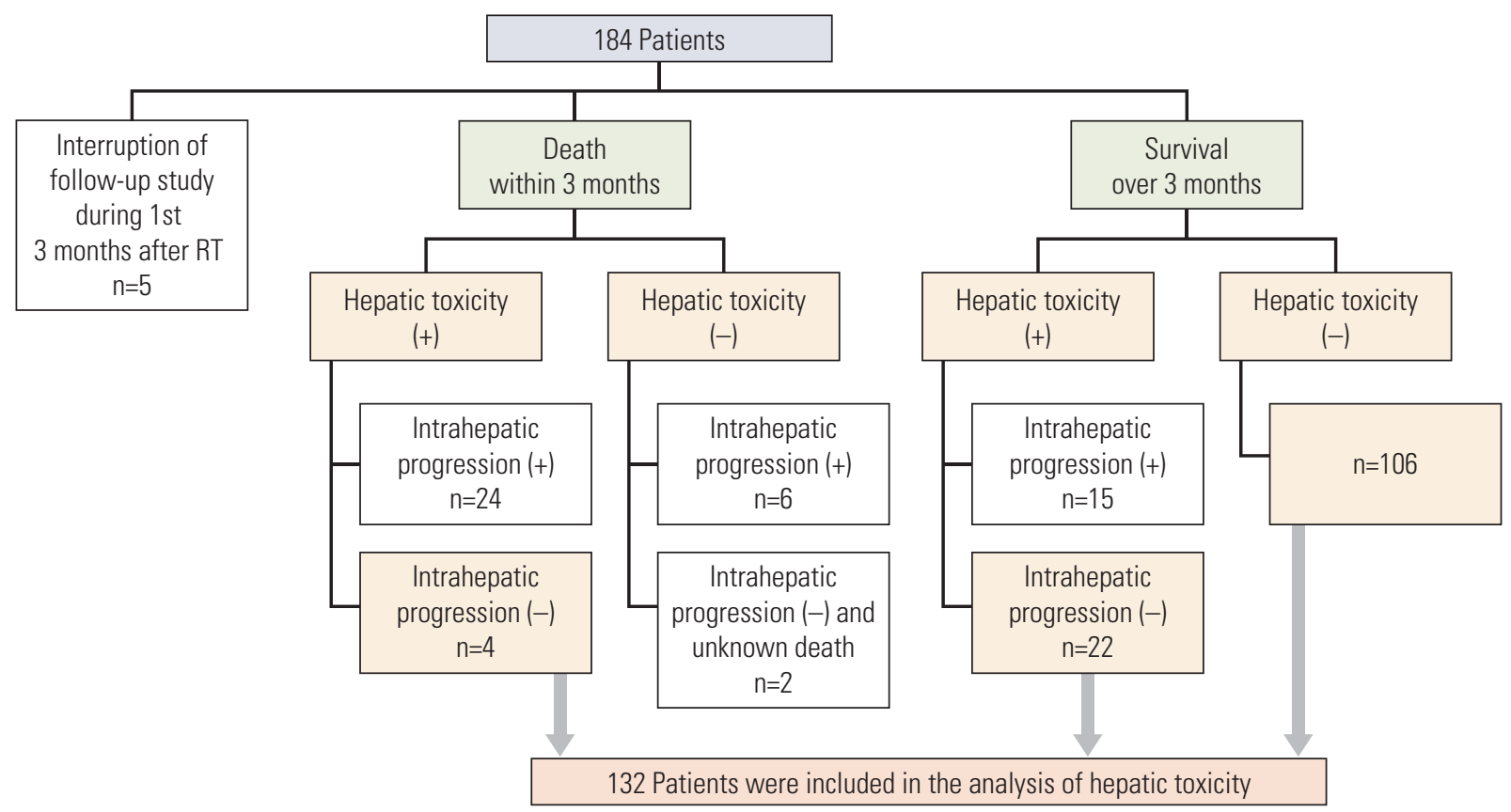

Fig. 1. Flowchart of evaluable patients' recruitment process for toxicity analysis.

dose of 2 Gy per fraction $\left(\mathrm{EQD}_{2}\right)$ using a linear-quadratic model when the $\alpha / \beta$ ratio for the normal liver was assumed to be $8 \mathrm{~Gy}\left(\mathrm{EQD}_{2}\right.$ with $\alpha / \beta$ ratio of $\left.8 \mathrm{~Gy}=\mathrm{EQD}_{2}{ }^{8}\right)$ [12]. This is applied to calculate the mean dose of the TLV (DTLV_mean $\left.\mathrm{EQD}_{2}{ }^{8}\right)$ and NLV $\left(\mathrm{D}_{\mathrm{NLV}}\right.$ mean, $\left.\mathrm{EQD}_{2}{ }^{8}\right)$, the percentage of the $\mathrm{TLV} \geq 5$ Gy $\left({ }_{\mathrm{\pi L}} \mathrm{V} 5 \mathrm{~Gy} \mathrm{EQD}{ }_{2}{ }^{8}\right), \geq 10 \mathrm{~Gy}\left({ }_{\mathrm{\pi L}} \mathrm{V}_{10} \mathrm{~Gy} \mathrm{EQD}_{2}{ }^{8}\right), \geq 15$ Gy $\left({ }_{\mathrm{\tau L}} \mathrm{V} 15 \mathrm{~Gy} \mathrm{EQD}{ }_{2}{ }^{8}\right), \geq 20 \mathrm{~Gy}\left({ }_{\mathrm{rL}} \mathrm{V} 20 \mathrm{~Gy} \mathrm{EQD}{ }_{2}^{8}\right), \geq 25 \mathrm{~Gy}\left({ }_{\mathrm{\pi L}} \mathrm{V} 25 \mathrm{~Gy}\right.$ $\left.\mathrm{EQD}_{2}{ }^{8}\right), \geq 30 \mathrm{~Gy}\left({ }_{\mathrm{\tau}} \mathrm{V} 30 \mathrm{~Gy} \mathrm{EQD}{ }_{2}{ }^{8}\right), \geq 35 \mathrm{~Gy}\left({ }_{\mathrm{\tau L}} \mathrm{V} 35 \mathrm{~Gy} \mathrm{EQD}{ }_{2}{ }^{8}\right)$, $\geq 40 \mathrm{~Gy}\left(\mathrm{rL} 40 \mathrm{~Gy} \mathrm{EQD}{ }^{8}\right)$, the percentage of the NLV $\geq 5$ Gy $\left({ }_{\mathrm{NL}} \mathrm{V} 5 \mathrm{~Gy} \mathrm{EQD}{ }_{2}^{8}\right), \geq 10 \mathrm{~Gy}\left({ }_{\mathrm{NL}} \mathrm{V} 10 \mathrm{~Gy} \mathrm{EQD}{ }_{2}^{8}\right), \geq 15 \mathrm{~Gy}\left({ }_{\mathrm{NL}} \mathrm{V} 15 \mathrm{~Gy}\right.$ $\left.\mathrm{EQD}_{2}{ }^{8}\right), \geq 20 \mathrm{~Gy}\left(\mathrm{NLV}_{20 \mathrm{~Gy} \mathrm{EQD}}{ }^{8}\right), \geq 25 \mathrm{~Gy}\left(\mathrm{NLV}_{2} 5 \mathrm{~Gy} \mathrm{EQD}_{2}{ }^{8}\right)$, $\geq 30$ Gy $\left({ }_{\mathrm{NLV}} \mathrm{V} 0 \mathrm{~Gy} \mathrm{EQD}_{2}{ }^{8}\right), \geq 35$ Gy $\left({ }_{\mathrm{NL}} \mathrm{V} 35 \mathrm{~Gy} \mathrm{EQD}_{2}{ }^{8}\right)$, and $\geq 40 \mathrm{~Gy}\left(\mathrm{NLV} 40 \mathrm{~Gy} \mathrm{EQD}_{2}{ }^{8}\right)$.

\section{Statistics}

Local progression was defined as tumor growth or regrowth in any direction beyond that on pre-RT images of treated lesions by the modified Response Evaluation Criteria in Solid Tumor. Intrahepatic progression was defined as any progression within the liver. Local progression-free survival (LPFS), intrahepatic progression-free survival (IHPFS), and overall survival (OS) rates were estimated using the Kaplan-Meier method from the date of start of RT. Patients were censored at the date of death or at the date of last known follow-up, whichever came first. Prognostic factors affecting OS were analyzed using the Kaplan-Meier method for univariate analysis. Multivariate analysis was performed using a Cox proportional hazards model. A p-value $<0.05$ was considered statistically significant.

To determine parameters affecting non-classic RILD in evaluable patients, clinical parameters were analyzed as categorical or continuous variables, and dosimetric parameters were analyzed as continuous variables. Univariate logistic regression analysis was performed to compare clinical and dosimetric parameters. In addition, a calculation of the area under the curve (AUC) of receiver operating characteristics (ROC) was used to determine the most predictive dosimetric parameter of non-classic RILD. As the AUC approximates 1.0, the parameter becomes more predictive of non-classic RILD. All calculations were performed using the Statistical Package for the Social Sciences software (SPSS ver. 20.0, IBM Corp., Armonk, NY).

\section{Ethical statement}

The current study was approved by the KROG (KROG 16-05) and the institutional review board of each participating institution (K-2016-2830). Written informed consent was waived due to the retrospective nature of the study. 
Table 1. Patients' characteristics at baseline

\begin{tabular}{|c|c|}
\hline Characteristic & No. of patients (\%) \\
\hline Age, median (range, yr) & $58(39-85)$ \\
\hline \multicolumn{2}{|l|}{ Sex } \\
\hline Male & $158(85.9)$ \\
\hline Female & $26(14.1)$ \\
\hline \multicolumn{2}{|l|}{ ECOG score } \\
\hline 0 & $54(29.3)$ \\
\hline 1 & $80(43.5)$ \\
\hline 2 & $50(27.2)$ \\
\hline \multicolumn{2}{|l|}{ Hepatitis } \\
\hline No & $11(6.0)$ \\
\hline $\mathrm{HBV}$ & $135(73.4)$ \\
\hline $\mathrm{HCV}$ & $25(13.6)$ \\
\hline Alcoholic & $13(7.0)$ \\
\hline \multicolumn{2}{|l|}{ Initial CP score } \\
\hline 7 & $114(62.0)$ \\
\hline 8 & $57(31.0)$ \\
\hline 9 & $13(7.0)$ \\
\hline Tumor size, median (range, $\mathrm{cm}$ ) & $5.4(1-21)$ \\
\hline \multicolumn{2}{|l|}{ No. of tumors } \\
\hline 1 & $83(45.1)$ \\
\hline $2-3$ & $54(29.4)$ \\
\hline $4-9$ & $23(12.5)$ \\
\hline$\geq 10$ & $24(13.0)$ \\
\hline \multicolumn{2}{|l|}{ Tumor location } \\
\hline One lobe & $131(71.2)$ \\
\hline Both lobes & $53(28.8)$ \\
\hline \multicolumn{2}{|l|}{ Bile duct invasion } \\
\hline No & $150(81.5)$ \\
\hline Yes & $34(18.5)$ \\
\hline \multicolumn{2}{|l|}{ PVTT } \\
\hline No & $62(33.7)$ \\
\hline Yes & $122(66.3)$ \\
\hline Main PVTT & $54(44.3)$ \\
\hline Branched PVTT & $68(55.7)$ \\
\hline \multicolumn{2}{|l|}{ mUICC_T } \\
\hline 1 & $10(5.4)$ \\
\hline 2 & $21(11.4)$ \\
\hline 3 & $61(33.2)$ \\
\hline 4 & $92(50.0)$ \\
\hline \multicolumn{2}{|l|}{ mUICC_N } \\
\hline 0 & $158(85.9)$ \\
\hline 1 & $26(14.1)$ \\
\hline \multicolumn{2}{|l|}{ Previous liver-directed therapy } \\
\hline No & $79(42.9)$ \\
\hline Yes & $105(57.1)$ \\
\hline \multicolumn{2}{|l|}{ Combined treatment } \\
\hline No & $70(38.0)$ \\
\hline Yes & $114(62.0)$ \\
\hline
\end{tabular}

(Continued)
Table 1. Continued

\begin{tabular}{lc}
\hline Characteristic & No. of patients (\%) \\
\hline Fraction size, median (range, Gy) & $2.5(1.5-5)$ \\
\hline BED, median (range, Gy $\left.{ }_{10}\right)$ & $56.0(40.4-89.6)$ \\
\hline RT completion & \\
$\quad$ Yes & $179(97.3)$ \\
$\quad$ No & $5(2.7)^{\mathrm{a})}$ \\
\hline AFP, median (range, IU/mL) & $242.7(0.7-1136990)$ \\
\hline Additional treatment & \\
\hline No & $95(51.6)$ \\
$\quad$ Yes & $89(48.4)$ \\
\hline
\end{tabular}

ECOG, Eastern Cooperative Oncology Group; HBV, hepatitis $\mathrm{B}$ virus; $\mathrm{HCV}$, hepatitis $\mathrm{C}$ virus; $\mathrm{CP}$, Child-Pugh; PVTT, portal vein tumor thrombosis; mUICC, the modified International Union Against Cancer stage; $\mathrm{T}$, tumor; $\mathrm{N}$, lymph nodes; $\mathrm{BED}$, biologically effective dose when the $\alpha / \beta$ ratio was assumed to be $10 \mathrm{~Gy}$; AFP, $\alpha$-fetoprotein. a)The cease of RT was due to patients' refusal $(n=2)$, decreased general performance $(\mathrm{n}=2)$; aggravation of hyperbilirubinemia $(\mathrm{n}=1)$.

\section{Results}

\section{Patients' characteristics}

Patients' characteristics at baseline are summarized in Table 1. Of 184 patients, the median age was 58 years. Viralassociated hepatitis due to hepatitis B or C virus was presented in $87.0 \%$ of patients. CP score was seven in 114 patients $(62.0 \%)$, eight in 57 patients $(31.0 \%)$, and nine in 13 patients $(7.0 \%)$. The median tumor size was $5.4 \mathrm{~cm}$. A single lesion was presented in $45.1 \%$ and portal vein tumor thrombosis (PVTT) was present in $66.3 \%$. One hundred five patients $(57.1 \%)$ had liver-directed therapy with 1-18 interventions (median, 2) before RT; $80.0 \%$ received transarterial chemoembolization (TACE). Combined treatment, defined as a treatment administered within 4 weeks of the start or end of RT, was conducted in 114 patients $(62.0 \%)$; the most common modality was TACE in 81 patients, followed by transcatheter arterial chemotherapy infusion (TACI) in 32 patients. Most patients $(87.5 \%$ ) received 3DCRT, and 53.8\% of patients received curative-intent RT, including all viable tumors. The total RT dose ranged from 31.5 to $64.0 \mathrm{~Gy}$ (median, $44.0 \mathrm{~Gy}$ ), and the fraction size ranged from 1.5 to 5.0 Gy (median, 2.5 Gy). Eighty-nine patients (48.4\%) underwent additional treatment after RT with 1-9 interventions (median, 2), including TACE (67 patients), TACI (15 patients), sorafenib (13 patients), systemic chemotherapy (6 pati- 


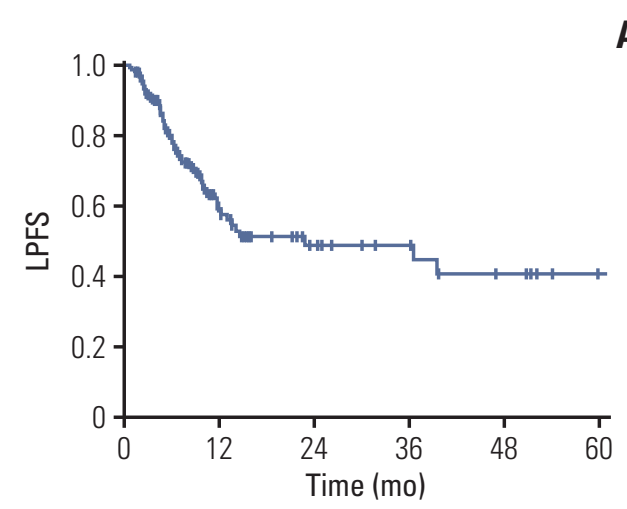

A

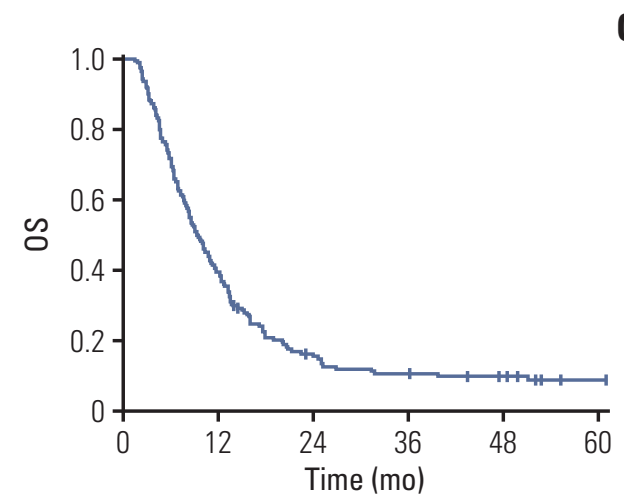

Fig. 2. Local progression-free survival (LPFS) (A), intrahepatic progression-free survival (IPFS) (B), and overall survival (OS) (C) curves.

A

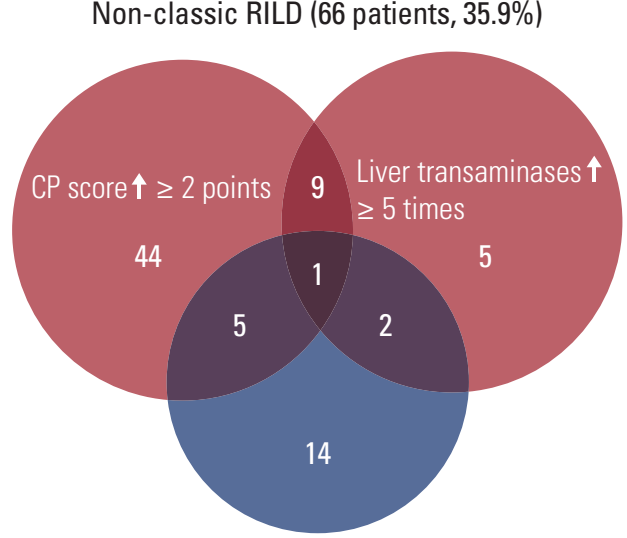

Classic RILD (22 patients, 12.0\%)

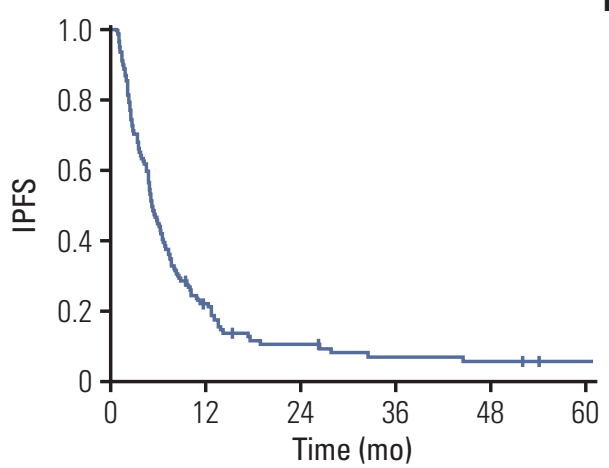

C
B 
Table 2. Univariate analysis and multivariate analysis for prognostic factors affecting OS

\begin{tabular}{|c|c|c|c|c|c|c|}
\hline Factor & $\begin{array}{c}\text { No. of } \\
\text { patients }\end{array}$ & $\begin{array}{l}1-Y e a r \\
\text { OS }(\%)\end{array}$ & $\begin{array}{l}\text { Median } \\
\text { OS (mo) }\end{array}$ & $\begin{array}{c}\text { UVA } \\
\text { p-value }\end{array}$ & $\begin{array}{c}\text { MVA } \\
\text { HR }(95 \% \text { CI })\end{array}$ & $\begin{array}{c}\text { MVA } \\
\text { p-value }\end{array}$ \\
\hline \multicolumn{7}{|l|}{ Age (yr) } \\
\hline$\leq 60$ & 107 & 30.8 & 8.3 & 0.154 & 0.722 & 0.104 \\
\hline$>60$ & 77 & 51.3 & 12.2 & & $(0.487-1.069)$ & \\
\hline \multicolumn{7}{|l|}{ Sex } \\
\hline Male & 158 & 35.8 & 9.1 & 0.055 & 1.174 & 0.622 \\
\hline Female & 26 & 60.6 & 13.4 & & $(0.621-2.219)$ & \\
\hline \multicolumn{7}{|l|}{ ECOG score } \\
\hline $0-1$ & 134 & 40.2 & 9.4 & 0.817 & - & - \\
\hline 2 & 50 & 37.2 & 9.7 & & & \\
\hline \multicolumn{7}{|l|}{ Hepatitis } \\
\hline No & 10 & 57.1 & 20.7 & 0.020 & Reference & 0.011 \\
\hline $\mathrm{HBV} / \mathrm{HCV}$ & 160 & 40.0 & 9.5 & & $\begin{array}{c}1.970 \\
(0.829-4.683)\end{array}$ & 0.125 \\
\hline Alcoholic & 14 & 19.0 & 5.3 & & $\begin{array}{c}4.559 \\
(1.570-13.235)\end{array}$ & 0.005 \\
\hline \multicolumn{7}{|l|}{ Initial CP score } \\
\hline 7 & 114 & 43.2 & 10.7 & 0.381 & - & - \\
\hline 8 & 57 & 35.5 & 9.1 & & & \\
\hline 9 & 13 & 23.1 & 5.6 & & & \\
\hline \multicolumn{7}{|c|}{ Tumor size $(\mathrm{cm})$} \\
\hline$\leq 5$ & 85 & 48.7 & 11.1 & 0.019 & - & - \\
\hline$>5$ & 99 & 31.4 & 8.0 & & & \\
\hline \multicolumn{7}{|l|}{ No. of tumors } \\
\hline $1-3$ & 137 & 43.6 & 10.1 & 0.014 & - & - \\
\hline$\geq 4$ & 47 & 26.7 & 8.0 & & & \\
\hline \multicolumn{7}{|c|}{ Tumor location } \\
\hline One lobe & 131 & 42.1 & 10.1 & 0.052 & - & - \\
\hline Both lobes & 53 & 32.6 & 8.2 & & & \\
\hline \multicolumn{7}{|l|}{ PVTT } \\
\hline No & 62 & 55.1 & 13.2 & $<0.001$ & 1.022 & 0.928 \\
\hline Yes & 122 & 31.6 & 8.0 & & $(0.636-1.643)$ & \\
\hline \multicolumn{7}{|l|}{ mUICC_T } \\
\hline 1,2 & 31 & 72.7 & 24.1 & $<0.001$ & 3.277 & 0.002 \\
\hline 3,4 & 153 & 32.5 & 8.3 & & $(1.546-6.944)$ & \\
\hline \multicolumn{7}{|l|}{ mUICC_N } \\
\hline 0 & 158 & 41.8 & 10.0 & 0.031 & 1.355 & 0.242 \\
\hline 1 & 26 & 22.8 & 6.4 & & $(0.815-2.254)$ & \\
\hline \multicolumn{7}{|c|}{ Initial AFP (IU/mL) } \\
\hline$\leq 200$ & 87 & 47.1 & 11.1 & 0.003 & 1.875 & 0.005 \\
\hline$>200$ & 92 & 29.2 & 8.0 & & $(1.207-2.911)$ & \\
\hline \multicolumn{7}{|l|}{ RT aima) } \\
\hline Curative & 99 & 43.2 & 10.1 & 0.044 & 0.876 & 0.486 \\
\hline Palliative & 85 & 34.8 & 8.3 & & $(0.604-1.271)$ & \\
\hline \multicolumn{7}{|l|}{ BED (Gy $\left.y_{10}\right)$} \\
\hline$\leq 53$ & 75 & 31.4 & 8.3 & 0.029 & 0.946 & 0.760 \\
\hline$>53$ & 109 & 45.1 & 10.1 & & $(0.664-1.349)$ & \\
\hline \multicolumn{7}{|l|}{ AFP response ${ }^{b)}$} \\
\hline Yes & 79 & 44.4 & 9.8 & 0.012 & 0.593 & 0.013 \\
\hline No & 81 & 24.2 & 6.6 & & $(0.393-0.894)$ & \\
\hline
\end{tabular}

(Continued to the next page) 
Table 2. Continued

\begin{tabular}{|c|c|c|c|c|c|c|}
\hline Factor & $\begin{array}{c}\text { No. of } \\
\text { patients }\end{array}$ & $\begin{array}{l}1-Y e a r \\
\text { OS }(\%)\end{array}$ & $\begin{array}{l}\text { Median } \\
\text { OS (mo) }\end{array}$ & $\begin{array}{c}\text { UVA } \\
\text { p-value }\end{array}$ & $\begin{array}{c}\text { MVA } \\
\text { HR }(95 \% \text { CI })\end{array}$ & $\begin{array}{c}\text { MVA } \\
\text { p-value }\end{array}$ \\
\hline \multicolumn{7}{|c|}{ Classic RILD } \\
\hline No & 162 & 41.2 & 9.7 & 0.582 & - & - \\
\hline Yes & 22 & 27.3 & 7.7 & & & \\
\hline \multicolumn{7}{|c|}{ Non-classic RILD } \\
\hline No & 118 & 51.3 & 12.2 & $<0.001$ & 2.674 & $<0.001$ \\
\hline Yes & 66 & 17.2 & 5.1 & & $(1.826-3.916)$ & \\
\hline \multicolumn{7}{|c|}{ Additional treatment } \\
\hline No & 95 & 27.0 & 7.0 & 0.001 & 2.159 & $<0.001$ \\
\hline Yes & 89 & 51.7 & 12.2 & & $(1.479-3.152)$ & \\
\hline
\end{tabular}

OS, overall survival; UVA, univariate analysis; MVA, multivariate analysis; $\mathrm{HR}$, hazard ratio; CI, confidence interval; ECOG, Eastern Cooperative Oncology Group; HBV, hepatitis B virus; HCV, hepatitis C virus; CP, Child-Pugh; PVTT, portal vein tumor thrombosis; mUICC, the modified International Union Against Cancer stage; T, tumor; N, lymph nodes; AFP, $\alpha$-fetoprotein; RT, radiotherapy; BED, biologically effective dose when the $\alpha / \beta$ ratio was assumed to be $10 \mathrm{~Gy}$; RILD, radiationinduced liver disease. a) Curative intent means that RT field cover all viable tumors; palliative intent means that RT field cover a part of viable tumors, ${ }^{b}$ Defined as AFP level reduction of $>20 \%$ from the initial level at 1 months after completion of RT in 160 patients who check follow-up AFP level.

ents), RT (5 patients), liver transplantation (5 patients), and radiofrequency ablation (1 patient).

\section{Outcomes}

The median follow-up period was 7.3 months (range, 0.7 to 67.7 months). The median OS was 9.4 months, and the actuarial 6-month and 1-year LPFS, IHPFS, and OS rates were $78.0 \%$ and $58.9 \%, 43.1 \%$ and $22.1 \%$, and $70.8 \%$ and $39.8 \%$, respectively (Fig. 2). Hepatic toxicity occurred in 80 patients (43.5\%) within 3 months after the end of RT; 22 patients (12.0\%) experienced classic RILD and 66 (35.9\%) experienced non-classic RILD (Fig. 3A). After the occurrence of classic RILD, 15 patients (68.2\%) recovered their own liver function: three patients $(13.6 \%)$ suffered from persistent hepatic dysfunction; four patients $(18.2 \%)$ experienced intrahepatic progression and were impossible to assess. Among patients with non-classic RILD, 10 patients $(15.2 \%)$ recovered their own liver function: 17 patients $(25.8 \%)$ suffered from persistent hepatic dysfunction; 39 patients $(59.0 \%)$ experienced intrahepatic progression and were impossible to assess. The results of the univariate and multivariate analysis for prognostic factors affecting OS are summarized in Table 2. In multivariate analysis, non-classic RILD (hazard ratio [HR], 2.674; $95 \%$ confidence interval [CI], 1.826 to $3.916 ; \mathrm{p}<0.001$ ) and additional treatment (HR, 2.159; 95\% CI, 1.479 to 3.152; $\mathrm{p}<0.001$ ) were the most significant factors affecting OS.

\section{Predictors for non-classic RILD}

In 132 evaluable patients described in Fig. 1, hepatic toxicity occurred in 37 patients $(28.0 \%)$ within 3 months after the end of RT. The characteristics are listed in S1 Table. Classic RILD occurred in 16 patients $(12.1 \%)$ and non-classic RILD occurred in 26 patients (19.7\%); among patients with nonclassic RILD, 23 patients experienced a worsening of CP score by $\geq 2$ points (Fig. 3B). Univariate logistic regression analysis was conducted to determine clinical and dosimetric parameters affecting non-classic RILD, which was the most significant prognostic factor for OS in both univariate and multivariate analysis. Of the clinical parameters, only the RT technique was associated with the risk of non-classic RILD $(\mathrm{p}=0.007)$ (S2 Table). Of the dosimetric parameters, NLV, $\mathrm{D}_{\text {TLV_mean }} \mathrm{EQD}_{2}{ }^{8}$, тLV15Gy $\mathrm{EQD}_{2}{ }^{8}$, тLV20Gy EQD ${ }_{2}{ }^{8},{ }_{\mathrm{rL}} \mathrm{V} 35 \mathrm{~Gy}$ $\mathrm{EQD}_{2}{ }^{8}$, and ${ }_{\mathrm{TL}} \mathrm{V} 40 \mathrm{~Gy} \mathrm{EQD}_{2}{ }^{8}$ were associated with the risk of non-classic RILD (Table 3). NLV was the most predictive dosimetric parameter based on compared values from the AUC of ROC.

\section{Discussion}

RT is mostly administered to HCC patients with CP-A, and only a few studies have examined the efficacy of RT for CP-B $[13,14]$. Culleton et al. [10] reported a median OS of 7.9 
Table 3. Univariate analysis for dosimetric parameters affecting non-classic radiation-induced liver disease

\begin{tabular}{|c|c|c|c|}
\hline Parameter & Mean \pm standard deviation & p-value & ROC AUC \\
\hline GTV (mL) & $287.7 \pm 585.7$ & 0.211 & 0.666 \\
\hline TLV (mL) & $1,555.8 \pm 758.7$ & 0.311 & 0.571 \\
\hline NLV (mL) & $1,184.4 \pm 442.2$ & 0.013 & 0.694 \\
\hline $\mathrm{D}_{\mathrm{TLV}_{-} \text {mean }} \mathrm{EQD}_{2}{ }^{8}(\mathrm{~Gy})^{\mathrm{a})}$ & $18.1 \pm 8.8$ & 0.041 & 0.593 \\
\hline${ }_{\mathrm{TL}} \mathrm{V} 5 \mathrm{~Gy} \mathrm{EQD}_{2}^{8}(\%)^{\mathrm{b})}$ & $71.8 \pm 17.3$ & 0.120 & 0.582 \\
\hline $\mathrm{TL} V 10 \mathrm{~Gy} \mathrm{EQD}_{2}^{8}(\%)$ & $58.9 \pm 18.3$ & 0.082 & 0.607 \\
\hline тLV15Gy EQD ${ }_{2}^{8}(\%)$ & $50.0 \pm 18.9$ & 0.023 & 0.644 \\
\hline $\mathrm{TLV} 20 \mathrm{~Gy} \mathrm{EQD}_{2}{ }^{8}(\%)$ & $43.2 \pm 19.6$ & 0.019 & 0.648 \\
\hline $\mathrm{TL} \mathrm{V} 25 \mathrm{~Gy} \mathrm{EQD}_{2}^{8}(\%)$ & $37.6 \pm 19.6$ & 0.051 & 0.618 \\
\hline $\mathrm{TL} \mathrm{V} 30 \mathrm{~Gy} \mathrm{EQD}_{2}^{8}(\%)$ & $32.7 \pm 19.9$ & 0.051 & 0.594 \\
\hline тLV35Gy EQD ${ }_{2}^{8}(\%)$ & $28.5 \pm 19.3$ & 0.039 & 0.595 \\
\hline $\mathrm{TL} V 40 \mathrm{~Gy} \mathrm{EQD}_{2}{ }^{8}(\%)$ & $21.8 \pm 19.5$ & 0.003 & 0.635 \\
\hline $\mathrm{D}_{\mathrm{NLV}_{\text {_mean }}} \mathrm{EQD}_{2}{ }^{8}(\mathrm{~Gy})$ & $13.9 \pm 5.4$ & 0.794 & 0.508 \\
\hline${ }_{\mathrm{NL}} \mathrm{V} 5 \mathrm{~Gy} \mathrm{EQD}_{2}{ }^{8}(\%)^{\mathrm{c})}$ & $68.7 \pm 17.4$ & 0.203 & 0.582 \\
\hline${ }_{\mathrm{NL}} \mathrm{V} 10 \mathrm{~Gy} \mathrm{EQD}_{2}^{8}(\%)$ & $53.0 \pm 16.2$ & 0.373 & 0.560 \\
\hline${ }_{\mathrm{NL}} \mathrm{V} 15 \mathrm{~Gy} \mathrm{EQD}{ }_{2}^{8}(\%)$ & $42.0 \pm 15.2$ & 0.190 & 0.592 \\
\hline${ }_{\mathrm{NLV}} 20 \mathrm{~Gy} \mathrm{EQD}_{2}^{8}(\%)$ & $34.1 \pm 14.4$ & 0.143 & 0.606 \\
\hline${ }_{\mathrm{NL}} \mathrm{V} 25 \mathrm{~Gy} \mathrm{EQD}_{2}{ }^{8}(\%)$ & $27.7 \pm 13.4$ & 0.495 & 0.551 \\
\hline${ }_{\mathrm{NL}} \mathrm{V} 30 \mathrm{~Gy} \mathrm{EQD}_{2}^{8}(\%)$ & $22.4 \pm 12.4$ & 0.470 & 0.551 \\
\hline${ }_{\mathrm{NL}} \mathrm{V} 35 \mathrm{~Gy} \mathrm{EQD}{ }_{2}^{8}(\%)$ & $17.9 \pm 11.3$ & 0.205 & 0.577 \\
\hline${ }_{\mathrm{NL}} \mathrm{V} 40 \mathrm{~Gy} \mathrm{EQD}_{2}{ }^{8}(\%)$ & $12.1 \pm 10.8$ & 0.057 & 0.591 \\
\hline
\end{tabular}

ROC, receiver operator characteristics; AUC, area under the curve; GTV, gross tumor volume; TLV, total liver volume; NLV, normal liver volume, which was defined as the total liver volume minus GTV in seven institutions and as the TLV minus the planning target volume in six institutions; $\mathrm{EQD}_{2}$, equivalent dose of $2 \mathrm{~Gy}$ per fraction. ${ }^{\mathrm{a})}$ Due to variations in the fractionation, all doses converted into the $\mathrm{EQD}_{2}$ using linear-quadratic model when the $\alpha / \beta$ ratio for the normal liver was assumed

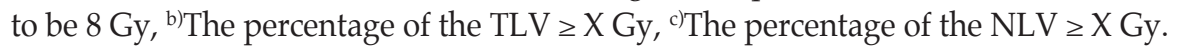

months in CP-B or -C patients treated with SBRT for HCC: 9.9 months in CP-B7 patients and 2.8 months in $\mathrm{CP} \geq 8$. In contrast, Nabavizadeh et al. [15] reported a superior survival rate of 11.8 months after SBRT or accelerated hypofractionated RT (AHRT). The authors suggested that favorable patients' characteristics, such as a unifocal tumor, smaller tumor size, and PVTT in $10 \%$ of patients, may have contributed to the improvement in OS. Our fractionated conformal RT showed a comparable survival of 9.4 months, despite the inclusion of patients with unfavorable characteristics, e.g., T3/T4, multiple HCCs, large tumor size, and PVTT. However, local control (LC) was suboptimal compared with SBRT studies with a 1-year LPFS rate of $58.9 \%$. Ohri et al. [16] found that there was no clear evidence for a dose-response relationship with a BED of 60-180 Gy 10 for SBRT to primary liver tumors and suggested that SBRT with 60-72 Gy10 was a reasonable fractionation scheme, with a 2-year LPFS of $90 \%$. In addition, Nabavizadeh et al. [15] showed statistically significant superior LC rates for SBRT group compared to AHRT group, with a 2-year LC rate of $94 \%$ vs. $65 \%$. How- ever, a nationwide survey in Korea reported that SBRT was selectively used for small-sized HCC with CP-A and that RT was mainly considered for advanced HCC and combined treatment using fractionated conformal RT was common clinical practice patterns $[17,18]$. In addition, HCC occurs in developing countries, especially in Asia where there are limited health resources. Therefore, we suggest that fractionated conformal RT as a practical alternative to SBRT, although further prospective studies to improve its efficacy are required.

The incidence of RILD after RT is higher in HCC patients with CP-B than with CP-A. An SBRT study for HCC in 29 patients with $\mathrm{CP}-\mathrm{B}$ or $-\mathrm{C}$ reported the highest toxicity rate of $63 \%$, resulting in a worsening of $\mathrm{CP}$ score by $\geq 2$ points after a median dose of $30 \mathrm{~Gy}$ in six fractions [10]. They suggested SBRT for selected CP-B7 patients but did not recommend it for patients with $\mathrm{CP} \geq 8$ outside of studies. Another study using SBRT (50 Gy in 5 fractions) or AHRT (45 Gy in 18 fractions) presented a worsening of $\mathrm{CP}$ score by $\geq 2$ points in 27 out of 95 patients (28\%) with CP-A or -B7 and in 18 out of 51 patients (35\%) with CP-B8, -B9, or -C [15]. As the true toler- 
ability of RT in patients with CP-B or $-\mathrm{C}$ is unknown, the authors proposed further prospective trials. In a hypofractionated 3DCRT study using 40-60 Gy with a fraction size of 4-8 Gy, classic or non-classic RILD occurred in 12 out of 20 patients (60\%) with CP-B, compared to 7 out of $108(6 \%)$ with CP-A [19]. They stated that CP-B patients did not tolerate the hypofractionated RT. On the other hand, conventional fractionated RT may be more tolerable. A 3DCRT study using 66 Gy in 33 fractions reported that three out of 11 patients $(27 \%)$ with CP-B experienced grade 4 hepatic toxicity [20]. However, as all of these patients had grade 3 abnormalities before $\mathrm{RT}$, the correlation of toxicity to the RT is not entirely clear. In the current study, non-classic RILD was observed in $19.7 \%$ of 132 evaluable patients after fractionated conformal RT with a median fraction size of $2.5 \mathrm{~Gy}$. Considering that normal tissue toxicity is more greatly impacted by fraction size in terms of radiobiology, we suggested the use of fractionated conformal RT for HCC in CP-B patients to minimize toxicity [21]. Because most patients were CP-B7 or -B8, however, the safety of fractionated conformal RT for patients with $\mathrm{CP}$ B9 has still undetermined and we should treat them with considerable caution.

To the best of our knowledge, this is the largest study in published data evaluating predictors for non-classic RILD in HCC patients with CP-B treated with fractionated conformal RT. Although several dosimetric parameters were statistically significant in univariate analysis, we were unable to identify the definite dosimetric constraints because values from the AUC of ROC were suboptimal for the selections of cut-off points. Other recent studies have attempted to obtain the definitive constraints in CP-B patients but did not succeed $[15,22]$. There are some practical limitations to identify dosimetric predictors. Firstly, our study applied various NLV definitions according to different institutions because plan data which was already approved before RT were retrospectively reviewed. In addition, we defined the $\alpha / \beta$ ratio of the normal liver as 8 to compare different fractionation schedules among institutions, based on the Korean data reflecting similarities in the underlying disease, applied fraction schemes, and combined modalities [12]. However, the $\alpha / \beta$ ratio of the normal liver is still unknown, and it ranges between 2, 2.5, 3, 8, and 10 [23-26]. These variances may confound the importance of dosimetric parameters. Secondly, RT for CP-B patients have a higher probability of RILD, especially non-classic RILD: however, the underlying pathology of non-classic RILD remains unclear [7]. Thirdly, CP-B, as a preexisting liver dysfunction, has the intrinsic morbidity. In a randomized trial in advanced HCC patients, the rate of serious adverse events among the placebo group because of progression of cirrhosis or HCC was 52\% [27]. However, it is impossible to distinguish between RILD and the natural progression of underlying cirrhosis in a clinical setting.
Therefore, further prospective studies are required to minimize confounding factors and obtain practical constraints.

There were some limitations to the current study. Firstly, there was the interinstitutional heterogeneity of HCC management, because the KLCSG and NCC practice guidelinerecommended RT only for HCC patients with well-preserved liver function (CP-A or upper B) and could not encompass all possible clinical situations. However, a certain degree of heterogeneity among institutions mirrors clinical practice in the real world, providing results more representative of what can be achieved in everyday practice than findings from an ideal setting [28]. This is particularly important for HCC as a large gap exists between applied practice and evidence-based treatment, making our multicenter study more representative [29]. Secondly, as we only included patients who received $\mathrm{RT} \geq 40 \mathrm{~Gy}_{10}$, patients who could not complete RT or decreased the total dose due to acute toxicities or other possible causes would be excluded. This may overestimate the efficacy of RT for patients with CP-B. Thirdly, this study was a retrospective analysis. Therefore, selection and confounding biases may have occurred, and the rates of hepatic toxicity may have been underestimated. To minimize the effect of these limitations, we only analyzed cases with completed follow-up during the 3 months after RT without disease progression.

In conclusions, fractionated conformal RT showed favorable OS when compared to other published studies in HCC patients with $\mathrm{CP}-\mathrm{B}$ and a moderate risk of non-classic RILD even if it was lower than that reported in previous SBRT studies. The individual RT for CP-B could be cautiously applied considering that non-classic RILD was the most significant factor affecting OS. In Korea, IMRT and proton beam therapy have been approved by the National Health Insurance Service from 2015. The application of these advanced RT techniques using fractionated RT might provide some answers to improve the efficacy of RT without increasing the incidence of non-classic RILD for HCC patients with CP-B.

\section{Electronic Supplementary Material}

Supplementary materials are available at Cancer Research and Treatment website (https: // www.e-crt.org).

\section{Conflicts of Interest}

Conflict of interest relevant to this article was not reported.

\section{Acknowledgments}

This work was supported by the Soonchunhyang University Research Fund. 


\section{Author Details}

Department of Radiation Oncology, ${ }^{1}$ Soonchunhyang University College of Medicine, Bucheon, ${ }^{2}$ Samsung Medical Center, Sungkyunkwan University School of Medicine, Seoul, ${ }^{3}$ Korea University Ansan Hospital, Ansan, ${ }^{4}$ Asan Medical Center, University of Ulsan College of Medicine, Seoul, ${ }^{5}$ Gangnam Severance Hospital, Yonsei University College of Medicine, Seoul, ${ }^{6}$ Severance Hospital, Yonsei University College of Medicine, Seoul, ${ }^{7}$ Center for Liver Cancer,
Research Institute and Hospital, National Cancer Center, Goyang, ${ }^{8}$ Chonnam National University Medical School, Gwangju, ${ }^{9}$ Dong-A University College of Medicine, Busan, ${ }^{10}$ Chonbuk National University Hospital, Jeonju, ${ }^{11}$ Seoul St. Mary's Hospital, College of Medicine, The Catholic University of Korea, Seoul, ${ }^{12}$ Uijeongbu St. Mary's Hospital, College of Medicine, The Catholic University of Korea, Uijeongbu, ${ }^{13}$ Dongsan Medical Center, Keimyung University School of Medicine, Daegu, Korea

\section{References}

1. Jemal A, Bray F, Center MM, Ferlay J, Ward E, Forman D. Global cancer statistics. CA Cancer J Clin. 2011;61:69-90.

2. European Association for the Study of the Liver; European Organisation for Research and Treatment of Cancer. EASLEORTC clinical practice guidelines: management of hepatocellular carcinoma. J Hepatol. 2012;56:908-43.

3. Pinter M, Trauner M, Peck-Radosavljevic M, Sieghart W. Cancer and liver cirrhosis: implications on prognosis and management. ESMO Open. 2016;1:e000042.

4. Granito A, Bolondi L. Non-transplant therapies for patients with hepatocellular carcinoma and Child-Pugh-Turcotte class B cirrhosis. Lancet Oncol. 2017;18:e101-12.

5. Emami B, Lyman J, Brown A, Coia L, Goitein M, Munzenrider JE, et al. Tolerance of normal tissue to therapeutic irradiation. Int J Radiat Oncol Biol Phys. 1991;21:109-22.

6. Feng M, Ben-Josef E. Radiation therapy for hepatocellular carcinoma. Semin Radiat Oncol. 2011;21:271-7.

7. Pan CC, Kavanagh BD, Dawson LA, Li XA, Das SK, Miften M, et al. Radiation-associated liver injury. Int J Radiat Oncol Biol Phys 2010;76(3 Suppl):S94-100.

8. Guha C, Kavanagh BD. Hepatic radiation toxicity: avoidance and amelioration. Semin Radiat Oncol. 2011;21:256-63.

9. Chino F, Stephens SJ, Choi SS, Marin D, Kim CY, Morse MA, et al. The role of external beam radiotherapy in the treatment of hepatocellular cancer. Cancer. 2018;124:3476-89.

10. Culleton S, Jiang H, Haddad CR, Kim J, Brierley J, Brade A, et al. Outcomes following definitive stereotactic body radiotherapy for patients with Child-Pugh B or C hepatocellular carcinoma. Radiother Oncol. 2014;111:412-7.

11. Korean Liver Cancer Study Group; National Cancer Center, Korea. Practice guidelines for management of hepatocellular carcinoma 2009. Korean J Hepatol. 2009;15:391-423.

12. Son SH, Jang HS, Lee H, Choi BO, Kang YN, Jang JW, et al. Determination of the $\alpha / \beta$ ratio for the normal liver on the basis of radiation-induced hepatic toxicities in patients with hepatocellular carcinoma. Radiat Oncol. 2013;8:61.

13. Rim CH, Seong J. Application of radiotherapy for hepatocellular carcinoma in current clinical practice guidelines. Radiat Oncol J. 2016;34:160-7.

14. Lock MI, Klein J, Chung HT, Herman JM, Kim EY, Small W, et al. Strategies to tackle the challenges of external beam radiotherapy for liver tumors. World J Hepatol. 2017;9:645-56.

15. Nabavizadeh N, Waller JG, Fain R 3rd, Chen Y, Degnin CR, Elliott DA, et al. Safety and efficacy of accelerated hypofractionation and stereotactic body radiation therapy for hepatocellular carcinoma patients with varying degrees of hepatic impairment. Int J Radiat Oncol Biol Phys. 2018;100:577-85.

16. Ohri N, Tome WA, Mendez Romero A, Miften M, Ten Haken RK, Dawson LA, et al. Local control after stereotactic body radiation therapy for liver tumors. Int J Radiat Oncol Biol Phys. 2018 Jan 6 [Epub]. https:// doi.org/10.1016/j.ijrobp.2017. 12.288 .

17. Cha H, Park HC, Yu JI, Kim TH, Nam TK, Yoon SM, et al. Clinical practice patterns of radiotherapy in patients with hepatocellular carcinoma: a Korean Radiation Oncology Group Study (KROG 14-07). Cancer Res Treat. 2017;49:61-9.

18. Bae SH, Kim MS, Jang WI, Kay CS, Kim W, Kim ES, et al. Practical patterns for stereotactic body radiotherapy to hepatocellular carcinoma in Korea: a survey of the Korean Stereotactic Radiosurgery Group. Jpn J Clin Oncol. 2016;46:363-9.

19. Liang SX, Zhu XD, Lu HJ, Pan CY, Li FX, Huang QF, et al. Hypofractionated three-dimensional conformal radiation therapy for primary liver carcinoma. Cancer. 2005;103:2181-8.

20. Mornex F, Girard N, Beziat C, Kubas A, Khodri M, Trepo C, et al. Feasibility and efficacy of high-dose three-dimensionalconformal radiotherapy in cirrhotic patients with small-size hepatocellular carcinoma non-eligible for curative therapies: mature results of the French Phase II RTF-1 trial. Int J Radiat Oncol Biol Phys. 2006;66:1152-8.

21. Milano MT, Constine LS, Okunieff P. Normal tissue toxicity after small field hypofractionated stereotactic body radiation. Radiat Oncol. 2008;3:36.

22. Velec M, Haddad CR, Craig T, Wang L, Lindsay P, Brierley J, et al. Predictors of liver toxicity following stereotactic body radiation therapy for hepatocellular carcinoma. Int J Radiat Oncol Biol Phys. 2017;97:939-46.

23. Dawson LA, Normolle D, Balter JM, McGinn CJ, Lawrence TS, Ten Haken RK. Analysis of radiation-induced liver disease using the Lyman NTCP model. Int J Radiat Oncol Biol Phys. 2002;53:810-21. 
24. Cheng JC, Wu JK, Lee PC, Liu HS, Jian JJ, Lin YM, et al. Biologic susceptibility of hepatocellular carcinoma patients treated with radiotherapy to radiation-induced liver disease. Int J Radiat Oncol Biol Phys. 2004;60:1502-9.

25. Dawson LA, Biersack M, Lockwood G, Eisbruch A, Lawrence TS, Ten Haken RK. Use of principal component analysis to evaluate the partial organ tolerance of normal tissues to radiation. Int J Radiat Oncol Biol Phys. 2005;62:829-37.

26. Kim TH, Kim DY, Park JW, Kim SH, Choi JI, Kim HB, et al. Dose-volumetric parameters predicting radiation-induced hepatic toxicity in unresectable hepatocellular carcinoma patients treated with three-dimensional conformal radiotherapy. Int J Radiat Oncol Biol Phys. 2007;67:225-31.
27. Llovet JM, Ricci S, Mazzaferro V, Hilgard P, Gane E, Blanc JF, et al. Sorafenib in advanced hepatocellular carcinoma. N Engl J Med. 2008;359:378-90.

28. Trevisani F, Santi V, Gramenzi A, Di Nolfo MA, Del Poggio P, Benvegnu L, et al. Surveillance for early diagnosis of hepatocellular carcinoma: is it effective in intermediate/advanced cirrhosis? Am J Gastroenterol. 2007;102:2448-57.

29. El-Serag HB, Siegel AB, Davila JA, Shaib YH, Cayton-Woody $\mathrm{M}$, McBride R, et al. Treatment and outcomes of treating of hepatocellular carcinoma among Medicare recipients in the United States: a population-based study. J Hepatol. 2006;44: 158-66. 